\title{
Investigation of AISI 441 Ferritic Stainless Steel and Development of Spinel Coatings for SOFC Interconnect Applications
}

Z. Yang, G. Xia, C. Wang, Z.Nie, J. Templeton, J. Stevenson, and $P$. Singh

Pacific Northwest National Laboratory

Richland, WA 99354

May 2008

Work Performed Under:

SECA Core Technology Program

Contract DE-AC05-76RL01830

Report Submitted to:

Ayyakkannu Manivannan, Travis Shultz and

Wayne Surdoval

National Energy Technology Laboratory, Pittsburgh, PA

Pacific Northwest National Laboratory

Richland, WA 99354 


\title{
DISCLAIMER
}

This report was prepared as an account of work sponsored by an agency of the United States Government. Neither the United States Government nor any agency thereof, nor Battelle Memorial Institute, nor any of their employees, makes any warranty, express or implied, or assumes any legal liability or responsibility for the accuracy, completeness, or usefulness of any information, apparatus, product, or process disclosed, or represents that its use would not infringe privately owned rights. Reference herein to any specific commercial product, process, or service by trade name, trademark, manufacturer, or otherwise does not necessarily constitute or imply its endorsement, recommendation, or favoring by the United States Government or any agency thereof, or Battelle Memorial Institute. The views and opinions of authors expressed herein do not necessarily state or reflect those of the United States Government or any agency thereof.

\author{
PACIFIC NORTHWEST NATIONAL LABORATORY \\ operated by \\ BATTELLE \\ for the \\ UNITED STATES DEPARTMENT OF ENERGY \\ under Contract DE-AC05-76RL01830
}

Printed in the United States of America
Available to DOE and DOE contractors from the Office of Scientific and Technical Information,
P.O. Box 62, Oak Ridge, TN 37831-0062;
ph: (865) 576-8401
fax: $(865)$ 576-5728
email: reports@adonis.osti.gov

\begin{abstract}
Available to the public from the National Technical Information Service, U.S. Department of Commerce, 5285 Port Royal Rd., Springfield, VA 22161 ph: (800) 553-6847 fax: $(703) 605-6900$ email: orders@ntis.fedworld.gov online ordering: http://www.ntis.gov/ordering.htm
\end{abstract}




Topical Report

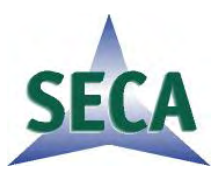

\section{Investigation of AISI 441 Ferritic Stainless Steel and Development of Spinel Coatings for SOFC Interconnect Applications}

Z. Yang, G. Xia, C. Wang, Z. Nie, J. Templeton, J. Stevenson, and P. Singh Pacific Northwest National Laboratory

Richland, WA 99354

May 2008

Work Performed Under:

SECA Core Technology Program

Contract DE-AC05-76RL01830

Report Submitted to:

Ayyakkannu Manivannan, Travis Shultz and

Wayne Surdoval

National Energy Technology Laboratory, Pittsburgh, PA

Pacific Northwest National Laboratory

Richland, WA 99354 
PNNL- 17568

\title{
Investigation of AISI 441 Ferritic Stainless Steel and Development of Spinel Coatings for SOFC Interconnect Applications
}

\author{
Zhenguo “Gary” Yang, Guan-Guang Xia, Chong-Min Wang, Zimin Nie, Joshua \\ Templeton, Jeff Stevenson, and Prabhakar Singh \\ Pacific Northwest National Laboratory, Richland, WA 99352
}

\begin{abstract}
As part of an effort to develop cost-effective ferritic stainless steel-based interconnects for solid oxide fuel cell (SOFC) stacks, both bare and spinel coated AISI 441 were studied in terms of metallurgical characteristics, oxidation behavior, and electrical performance. The conventional melt metallurgy used for the bulk alloy fabrication leads to significant processing cost reduction and the alloy chemistry with the presence of minor alloying additions of $\mathrm{Nb}$ and Ti facilitate the strengthening by precipitation and formation of Laves phase both inside grains and along grain boundaries during exposure in the intermediate SOFC operating temperature range. The Laves phase formed along the grain boundaries also ties up Si and prevents the formation of an insulating silica layer at the scale/metal interface during prolonged exposure. The substantial increase in ASR during long term oxidation due to oxide scale growth suggested the need for a conductive protection layer, which could also minimize $\mathrm{Cr}$ evaporation. In particular, $\mathrm{Mn}_{1.5} \mathrm{Co}_{1.5} \mathrm{O}_{4}$ based surface coatings on planar coupons drastically improved the electrical performance of the 441, yielding stable ASR values at $800^{\circ} \mathrm{C}$ for over 5,000 hours. Ce-modified spinel coatings retained the advantages of the unmodified spinel coatings, and also appeared to alter the scale growth behavior beneath the coating, leading to a more adherent scale. The spinel protection layers appeared also to improve the surface stability of 441 against the anomalous oxidation that has been observed for ferritic stainless steels exposed to dual atmosphere conditions similar to SOFC interconnect environments. Hence, it is anticipated that, compared to unmodified spinel coatings, the Ce-modified coatings may lead to superior structural stability and electrical performance. There is, however, a need to develop and validate the coating for larger, shaped interconnects. It should also be noted that the alloy oxidation and corrosion resistance in fuel compositions (syn gas, hydrocarbons, etc) and fuel utilizations (up to $85 \%$, for example) of practical interest have not yet been studied.
\end{abstract}

\section{Introduction}

Oxidation resistant ferritic stainless steels are considered to be promising candidate materials for interconnect applications in SOFC stacks operating in the intermediate temperature range of $650-850^{\circ} \mathrm{C}$. One issue associated with the use of 
conventional steels in this application, however, is the high electrical resistance and physical degradation that can result from the growth of the oxide scale on the alloy surface during high temperature exposure. For steels containing sufficient residual silicon, such as AISI 430, electrical resistance can be further increased by the formation of a continuous insulating silica layer at the scale/alloy interface. Low Si ferritic alloys have been developed for interconnect applications (e.g., Crofer22APU), but the required additional processing to remove the Si substantially increases the material cost.

Alternatively, modification of the alloy chemistry can potentially be used to avoid silica layer formation without the need for expensive vacuum refining steps. For example, Dulieu et al. ${ }^{1}$ reported that alloy 1.4509 (German specification, analogous to AISI 441), which is similar in many respects to 1.4016 (AISI 430), did not form a silica sub-layer at the scale/alloy interface, in spite of the presence of over $0.5 \%$ residual $\mathrm{Si}$ in both alloys. The primary difference in the composition of the two alloys is the presence of small amounts of $\mathrm{Nb}$ and $\mathrm{Ti}$ in 1.4509, suggesting that these additives played a key role in preventing Si migration to the scale/alloy interface.

Based on this encouraging result, PNNL has investigated the metallurgical characteristics, oxidation behavior, and electrical performance of AISI 441. In addition, benefits of protective air-side interconnect coatings have been examined by applying spinel-based coatings to AISI 441, and comparing the behavior of the coated steel to that of uncoated steel. Results of these investigations are summarized in this report.

\section{Experimental Procedure}

The ferritic stainless steel studied was AISI 441, a commercial grade steel manufactured by Allegheny Technologies Inc. The chemical analysis provided by the manufacturer indicated an alloy composition of $17.6 \%$ (weight) $\mathrm{Cr}, 0.33 \% \mathrm{Mn}, 0.47 \% \mathrm{Si}$, 0.46\% Nb, 0.18\% Ti, 0.20\% Ni, 0.01\% C, 0.045\% Al, 0.024\% P, 0.001\% S, balance Fe. As received steel coupons (25 mm x $12.5 \mathrm{~mm} \times 1.5 \mathrm{~mm}$ ) were cleaned in an ultrasonic acetone bath for five minutes and then rinsed with alcohol prior to oxidation or electrical testing, or application of a spinel coating. $\mathrm{Mn}_{1.5} \mathrm{Co}_{1.5} \mathrm{O}_{4}(\mathrm{MC})$ and $\mathrm{Ce}_{0.05} \mathrm{Mn}_{1.475} \mathrm{Co}_{1.475} \mathrm{O}_{4}$ (Ce-MC) spinel powders were prepared via glycine-nitrate combustion synthesis and applied to selected alloy coupons using a slurry-based approach. ${ }^{2}$ After coating, the dried coupons were first heat-treated in a reducing environment $\left(2.75 \% \mathrm{H}_{2} / 3 \% \mathrm{H}_{2} \mathrm{O} /\right.$ balance Ar) for two hours and then oxidized in ambient air at $800^{\circ} \mathrm{C}$ for one hour.

Bare and coated steel coupons were evaluated via isothermal oxidation tests in ambient air. The isothermal oxidation testing in air was performed by suspending the bare or coated coupons from an alumina rod in a tube furnace. A steady flow of ambient air ( $1-2 \%$ water) was provided throughout the oxidation tests. The oxidized coupons were weighed before and after heat treatment, and then subjected to microstructural characterization. Dual atmosphere tests (simultaneous exposure to air and hydrogen, both with $~ 3 \%$ H2O) were also performed, following the procedure described in Ref. 3. The electrical resistance of bare and coated 441 was measured using a four-probe DC technique. $\left(\mathrm{La}_{0.8} \mathrm{Sr}_{0.2}\right)_{0.98} \mathrm{MnO}_{3}$ (LSM) contact paste was applied between two identical steel coupons and Pt leads were spot-welded to the coupons. During the resistance tests, a constant current density of $500 \mathrm{~mA} . \mathrm{cm}^{-2}$ was applied to the coupons. Details of the test arrangement were reported in a previous publication. ${ }^{4} \mathrm{XRD}, \mathrm{SEM} / \mathrm{EDS}$, and TEM/EDS analyses were performed on selected samples. 


\section{Results and Discussion}

\section{A. Properties of Ferritic Stainless Steel 441}

1. Metallurgy of 441

Figure 1 shows an SEM image of a polished cross section of the as-received 441. Differences in contrast resulting from different crystal orientations revealed that the grains ranged in size from around 20 to 60 microns. Second phases (white in appearance) were observed to be randomly distributed within the grains. SEM/EDS point analysis indicated that the second phases were rich in $\mathrm{Nb}$ and $\mathrm{Ti}$, but contained little, if any, Si. This was further confirmed by TEM analysis, which indicated that the intra-grain precipitates were a Laves phase, which is consistent with the $\mathrm{Fe}_{2} \mathrm{Nb}$ Laves phase reported in the manufacturer's technical data "blue sheet" for $441 .{ }^{4}$

After oxidation in air at $800^{\circ} \mathrm{C}$ for 300 hours, second phase formation was observed at the grain boundaries, as shown in Figure 2. TEM analysis indicated that the grain boundary phase was a Laves phase rich in both $\mathrm{Nb}$ and $\mathrm{Si}$, in contrast to the initial intra-grain precipitates, which contained little, if any, Si.

\section{Oxidation Behavior of 441}

Figure 3 shows the oxidation behavior, in terms of weight gain as a function of time, of 441 at $800^{\circ} \mathrm{C}$ in flowing air. The weight gain due to the surface oxide scale growth approximately followed the classic Wagner parabolic relationship with time. The oxidation rate was similar to that previously measured for Crofer22APU, and slightly lower than that reported for AISI 430 under similar testing conditions. ${ }^{1,6} \mathrm{X}$-ray diffraction and cross-sectional SEM/EDS analysis on the oxidized samples confirmed that, as in the case of Crofer22APU, the scale grown on 441 had a bi-layer structure with a Mn-Cr spinel top layer and a chromia-rich sub-layer. ${ }^{6}$ No spallation was observed in the early stages of oxidation, but after 900 hours, localized scale spallation was observed, with the spallation edges coinciding with grain boundaries (Figure 4). Occasional delamination observed at the scale/alloy interface during cross-sectional analysis provided qualitative evidence that the bonding of the scale to the steel substrate was weaker than that previously observed for Crofer22APU, possibly due to the absence of rare earth elements in the 441 substrate (see discussion below). Exposure to a reducing environment (moist hydrogen) resulted in predominantly compact scale formation very similar in structure and chemistry to that observed after air exposure. Selected areas indicated porosity near the scale-metal interface. The scale did not show any evidence of spallation. This observation is in agreement with the observations on 441 by Chandra-Ambhorn et al., who also found higher adhesion energy for the scale in the reducing environment compared to the adhesion energy for the air-grown scale.

\section{Electrical Performance of 441}

In addition to satisfactory structural and surface stability, candidate interconnect alloys must also provide low electrical resistance in order to minimize power loss. Figure 5 shows the area specific resistance (ASR) of 441 as a function of time, measured in air at $800^{\circ} \mathrm{C}$. The 441 exhibited an initially low ASR that increased steadily over time due to 
oxide scale growth, reaching $\sim 20 \mathrm{~m} \Omega . \mathrm{cm}^{2}$ after 500 hours. Figure 6 shows an SEM crosssection image of the 441 and LSM contact material after the electrical measurement. A uniform scale was grown on the 441 substrate, which appeared to have reacted with the LSM contact material at their interface to form a dense interfacial layer. Importantly, there was no silica layer formation at the scale/metal interface, in spite of the relatively high residual Si content $(0.47 \%)$ in the steel. This is attributed to the observed incorporation of Si into the grain boundary Laves phase, thereby reducing Si activity in the steel substrate and inhibiting the formation of an insulating interfacial silica layer.

\section{B. Properties of Spinel-Coated Ferritic Stainless Steel 441}

As mentioned above, chromia-forming ferritic stainless steels such as 441 are promising candidate materials for interconnects in SOFC stacks. During long-term operation, however, materials-related challenges may arise, including surface instability (including oxidation, spallation, and reactions with neighboring components), increasing electrical resistance due to continuous oxide scale growth, and chromia-scale evaporation, which may lead to cathode poisoning.

One promising approach to overcome these issues is surface-modification of the metallic interconnects with conductive oxide coatings. For example, $(\mathrm{Mn}, \mathrm{Co})_{3} \mathrm{O}_{4}$ spinel coatings on stainless steel interconnects have been demonstrated to be effective in limiting inward oxygen and outward chromium diffusion., ${ }^{2,4,8-11}$ As a result, spinel coatings are expected to improve stack performance by enhancing oxidation resistance and avoiding Cr poisoning. To fully utilize these advantages of the coatings, however, adequate adherence at the interfaces between the coating, the scale grown beneath the coating, and the metal substrate is also required.

One well-established way to improve scale adherence to stainless steel substrates is to add small amounts of rare earth (RE) element(s) into the alloy. An alternative approach is to modify the alloy surface by deposition or coating with RE, usually in the form of oxides. ${ }^{12-15}$ For example, Alman el al. ${ }^{16,17}$ reported improved oxidation resistance after surface treatment of ferritic stainless steels with Ce, via a pack cementation-based process. Preliminary testing at PNNL indicated that the surface treatment led to reduced ASR, at least in the hundreds of hours time frame. However, to obtain satisfactory longterm oxidation resistance, and to minimize Cr volatility, a protective coating (either on a bare or Ce surface-modified alloy) may be required. Recently, PNNL has worked to obtain the benefits of a spinel coating and a Ce surface treatment in a single fabrication step by the application of spinel coatings modified with Ce. Specifically, $\mathrm{Mn}_{1.5} \mathrm{Co}_{1.5} \mathrm{O}_{4}$ spinel was modified by addition of Ce (the nominal composition was $\mathrm{Ce}_{0.050} \mathrm{Mn}_{1.475} \mathrm{Co}_{1.475} \mathrm{O}_{4}$ ) and then applied as a coating onto 441, which, as noted above, contains no RE additions. The properties of 441 with the Ce-modified spinel coating (Ce$\mathrm{MC}$ ) were investigated and compared to the properties of both uncoated 441 and 441 coated with the "standard" $\mathrm{Mn}_{1.5} \mathrm{Co}_{1.5} \mathrm{O}_{4}$ spinel (MC).

\section{Oxidation Behavior of Spinel-Coated 441}

Figure 3 shows the oxidation behavior, in terms of weight gain as a function of time, of MC and Ce-MC coated 441 at $800^{\circ} \mathrm{C}$ in air. It is clear that, during the 1200 hours of testing, the oxidation rate of the 441 was substantially reduced by the presence of the spinel coatings. Since the coatings appeared to provide a diffusion barrier to air 
(i.e., with closed pore microstructure), the observed weight change of the coated samples is attributed to oxygen ion inward diffusion through the coating leading to subsequent scale growth beneath the coating.

Further insight into the effects of the coatings can be gained from Figure 7, which shows the oxidation behavior of bare and coated 441 at $850^{\circ} \mathrm{C}$ in air. During the early stages of the oxidation, the weight gain due to scale growth beneath the coatings was similar, but, after $\sim 600$ hours of oxidation, the net weight gain of the samples with the MC coatings leveled off and dropped to near zero after 900 hours. Spallation of the MC coating was visually observed after the test, and SEM analysis indicated that the spallation occurred along the scale/metal interface. In comparison, the weight of the samples with the Ce-MC coatings continued to increase (at a much lower rate than the uncoated 441) during the whole test, and no spallation was observed on the Ce-MC coated samples, either visually and microscopically. These results suggest that the addition of Ce to the coating material led to a beneficial RE effect of scale adherence.

2. $\quad$ Electrical Performance of Spinel-Coated 441

Figure 5 shows ASR of bare, MC, and Ce-MC spinel-coated 441 as a function of time at $800^{\circ} \mathrm{C}$ in air. The beneficial effect of the spinel coatings on ASR is clearly apparent. While the electrical performance of the $\mathrm{MC}$ and $\mathrm{Ce}-\mathrm{MC}$ spinel coated coupons was similar, the structure and properties of the interface between the metal substrate and the oxide scale grown beneath the coatings appeared to differ. SEM cross-section analyses on tested samples with the MC coating revealed cracks or gaps along the scale/metal interface (Figure 8(a)). Though the cracks were likely generated during the cooling at the end of the test or during sample polishing for SEM analysis, they are qualitative indicators of relatively poor bonding at the scale/metal interface, and were consistent with other test results described above. In contrast, the scale grown beneath the Ce-MC coating (Figure 8(b)) remained adherent to the metal substrate, with no noticeable cracks or detachment along the interface. Both the MC and Ce-MC coatings were effective barriers to Cr-outward diffusion, though some Fe diffusion into the spinel coatings was evident, as indicated by SEM/EDS analyses shown in Figure 9. Although the EDS line scan did not clearly reveal Ce in the Ce-MC coating, point EDS analyses indicated the presence of ceria as a second phase (shown as white spots in Figure 9(b)) finely dispersed in the coating matrix. Thus, it appears that there was limited, if any, solubility of $\mathrm{Ce}$ in $(\mathrm{Mn}, \mathrm{Co})_{3} \mathrm{O}_{4}$, leading to subsequent precipitation of the second phase. Overall, the most important difference between the MC and Ce-MC coatings was the apparent improvement in scale adherence and thus scale/metal interfacial stability when Ce was included in the spinel coating composition.

Figure 10 shows ASR of bare, MC, and Ce-MC spinel-coated 441 as a function of time at $850^{\circ} \mathrm{C}$ in air. Once again, the beneficial effect of the spinel coatings on ASR is evident. SEM analysis of the tested samples clearly demonstrated the benefit of the Ce addition to the coating. The MC coating, and the scale grown beneath it, exhibited buckling on the 441 surface (see Figure 11(a)), and detachment occurred along the scale/metal interface, as shown in the inset in Figure 11(a). The buckling and detachment likely occurred during the cooling after the end of the test, as the electrical performance remained stable throughout the test. In contrast, the Ce-MC coating, and the scale grown beneath it, were well adherent to the metal substrate, and no cracking was observed along 
the scale/metal interface (see Figure 11(b)). SEM/EDS analysis found no evidence of $\mathrm{Cr}$ penetration into either the MC or Ce-MC coatings.

In addition to the above tests, long-term ASR tests on bare and spinel-coated 441 are also in progress. As shown in Figure 12, the ASR of bare 441 increased to 60 $\mathrm{m} \Omega . \mathrm{cm}^{2}$ after $\sim 5,000$ hours in air at $800^{\circ} \mathrm{C}$. In contrast, the samples coated with MC spinel and Ce-MC spinel exhibited stable ASR of $\sim 10-13 \mathrm{~m} \Omega . \mathrm{cm}^{2}$. It should be noted that the tests were interrupted twice by unscheduled power outages at around 650 and 2,800 hours. The unscheduled thermal events resulted in a step change and increase in the ASR of bare 441, possibly indicating damage to the interfacial contact or detachment of the scale from the metal substrate. In contrast, the ASRs of the coated samples returned to their previous level, suggesting that the coatings improved the stability of the contact material/coating/steel interface. For comparison, ASR results for MC spinelcoated Crofer22APU tested previously under identical conditions are also shown in Figure 12. Clearly, the electrical performance of the two coated alloys was very similar.

\section{Dual Atmosphere Testing of Spinel-Coated 441}

Previous studies found that the oxidation behavior of ferritic stainless steels under the dual atmosphere conditions experienced by SOFC interconnects can differ significantly from the behavior observed under single atmosphere conditions. In particular, when ferritic stainless steels were simultaneously exposed to air on one side and moist hydrogen at the other, the scale growth on the air side differed from the scale growth observed during exposure to air only. AISI430, with $17 \% \mathrm{Cr}$, suffered localized accelerated oxidation via the formation of $\mathrm{Fe}_{2} \mathrm{O}_{3}$ hematite nodules on the air side when exposed to ambient air $\left(\sim 1-2 \% \mathrm{H}_{2} \mathrm{O}\right)$ vs. moist hydrogen $\left(\sim 3 \% \mathrm{H}_{2} \mathrm{O}\right)$ at $800^{\circ} \mathrm{C}$. Crofer22APU, with a higher Cr content ( 23\% Cr) did not exhibit localized nodule growth under those conditions, but hematite nodules did nucleate and grow in the air side scale when ambient air was replaced by moist air $\left(\sim 3 \% \mathrm{H}_{2} \mathrm{O}\right){ }^{3,18} \mathrm{MC}$ spinel coatings applied to the air side have been found to be effective in suppressing this anomalous oxidation behavior in Crofer22APU. Recently, PNNL performed similar tests (moist air vs. moist hydrogen) on 441 with an air side Ce-MC coating. It should be noted that the 441 coupons were approximately $3 x$ thicker $(1.5 \mathrm{~mm}$ vs. $0.5 \mathrm{~mm})$ than the previously tested Crofer22APU. As in the case of MC-coated Crofer22APU, no anomalous oxidation behavior (such as hematite nodule formation) was observed on the air side of the Ce-MC coated 441 after 1000 hours of heat treatment at either 800 or $850^{\circ} \mathrm{C}$. Figure 13 shows the SEM/EDS analysis on the air side of Ce-MC coated 441 that was simultaneously exposed to $97 \% \mathrm{H}_{2}+3 \% \mathrm{H}_{2} \mathrm{O}$ on the other side during the 1,000 hours tests at $850^{\circ} \mathrm{C}$. For the purpose of comparison, the analysis on Ce-MC coated 441 that was exposed to air on both sides during the same test is also included. The Ce-MC coating on the air side appeared to be less dense than the coating on the sample that was exposed to air on both sides. The higher density of the coating on the sample exposed to air only may be related to the diffusion of Fe into the coating during the oxidation test, as diffusion of Fe appeared to be inhibited under the dual atmosphere exposure conditions. Nevertheless, air side coating on the dual atmosphere sample, which consisted of a dense inner layer and a porous outer layer, appeared to be effective in preventing spallation and detachment along the coating/scale/metal interfaces. 


\section{Conclusions}

Investigations into the metallurgy, oxidation behavior, and electrical performance indicate that the alloy metallurgy and chemistry of 441 ferritic stainless steel remains promising for SOFC interconnect applications.

- The conventional melt metallurgy used for the bulk alloy fabrication leads to significant processing cost reduction and the alloy chemistry with the presence of minor alloying additions of $\mathrm{Nb}$ and $\mathrm{Ti}$ facilitate the strengthening by precipitation and formation of Laves phase both inside grains and along grain boundaries during exposure in the intermediate SOFC operating temperature range. The Laves phase formed along the grain boundaries also ties up Si and prevents the formation of an insulating silica layer at the scale/metal interface during prolonged exposure.

- The substantial increase in ASR during long term oxidation due to oxide scale growth suggested the need for a conductive protection layer, which could also minimize $\mathrm{Cr}$ evaporation. In particular, air side $\mathrm{Mn}_{1.5} \mathrm{Co}_{1.5} \mathrm{O}_{4}$ based surface coatings on planar coupons drastically improved the electrical performance of the ferritic stainless steel 441 , yielding stable ASR values at $800^{\circ} \mathrm{C}$ for over 5,000 hours. There is a need to develop and validate the coating for larger, shaped interconnects.

- Ce-modified spinel coatings retained the advantages of the unmodified spinel coatings, and also appeared to alter the scale growth behavior beneath the coating, leading to a more adherent scale. Hence, it is anticipated that, compared to unmodified spinel coatings, the Ce-modified coatings may lead to superior structural stability and electrical performance when applied to commercial grade ferritic stainless steels (such as 441) for SOFC interconnect applications.

- The spinel protection layers appeared also to improve the air side surface stability of 441 against the anomalous oxidation that has been observed for ferritic stainless steels exposed to dual atmosphere conditions similar to SOFC interconnect environments. It should be noted that the alloy oxidation and corrosion resistance have not yet been evaluated in fuel compositions (syn gas, hydrocarbons, etc) and fuel utilizations (up to $85 \%$, for example) of practical interest.

\section{Acknowledgements}

The authors would like to thank Jim Rakowski at Allegheny Technologies, Inc. for providing the 441 alloy samples and for helpful discussions, and Paul Jablonsky at NETL-Albany for providing Ce surface-treated 441 samples and helpful discussions. Nat Saenz, Shelly Carlson, and Jim Coleman at PNNL performed metallographic sample preparation and SEM analysis. The authors would also like to acknowledge helpful discussions with Wayne Surdoval, Ayyakkannu Manivannan, and Briggs White at the National Energy Technology Laboratory (NETL). The work summarized in this paper was funded by the U.S. Department of Energy's Solid-State Energy Conversion Alliance (SECA) Core Technology Program. PNNL is operated by Battelle Memorial Institute for the U.S. Department of Energy under Contract DE-AC06-76RLO 1830. 


\section{References}

1. D. Dulieu, J. Cotton, H. Greiner, K. Honegger, A. Scholten, and T. Seguelong, in Proc. $3^{\text {rd }}$ Eur. SOFC Forum, Ed., P. Stevens, European Solid Oxide Fuel Cell Forum, Switzerland, p. 447 (1998).

2. Z.G. Yang, G.-G. Xia, S.P. Simner, and J.W. Stevenson, J. Electrochem. Soc., 152, A1896 (2005).

3. Z.G. Yang, M.S. Walker, P. Singh, J.W. Stevenson, and T. Norby, J. Electrochem. Soc., 151, B669 (2004).

4. Z.G. Yang, G. Xia, and J.W. Stevenson, Electrochem. \& Solid State Lett., $\underline{8}$, A168 (2005).

5. "Stainless Steel AL 441HP ${ }^{\mathrm{TM}}$ Alloy," Technical Data Blue Sheet, Allegheny Technologies, Inc. (2005).

6. Z.G. Yang, J.S. Hardy, M.S. Walker, G. Xia, S.P. Simner, and J.W. Stevenson, J. Electrochem. Soc., 151, A1825 (2004).

7. S. Chandra-Ambohrn, Y. Wouters, L. Antoni, F. Toscan, and A. Galerie, J. Power Sources, 171, 688 (2007).

8. Y. Larring and T. Norby, J. Electrochem. Soc., 147, 3251 (2000).

9. X. Chen, P.Y. Hou, C.P. Jacobson, S.J. Visco and L.C. De Jonghe, Solid State Ionics, 176,425 (2005).

10. M. Zahid, F. Tietz, D. Sebold and H.P. Buchkremer, in Proc. $6^{\text {th }}$ European SOFC Forum, Ed., M. Mogensen, pp. 820-827, European Solid Oxide Fuel Cell Forum, Switzerland (2004).

11. V.I. Gorokhovsky, P.E. Gannon, M.C. Deibert, R.J. Smith, A. Kayani, M. Kopczyk, D. VanVorous, Z. Yang, J.W. Stevenson, S. Visco, C. Jacobson, H. Kurokawa and S.W. Sofie, J. Electrochem. Soc., 153, A1886 (2005).

12. E. Lang, "The Role of Active Elements in the Oxidation Behaviour of High

Temperature Metals and Alloys,” Elsevier Applied Science, London, 1989.

13. J. Stringer, B.A. Wilcox, R.I. Jaffee, Oxid. Met., $\underline{5}, 11$ (1972).

14. D.P. Whittle, J. Stringer, Philos. Trans R. Soc. London Ser. A, 295, 145 (1980).

15. P. Hou and J. Stringer, J. Electrochem. Soc, 134, 1836 (1987).

16. D.E. Alman, C.D. Johnson, W.K. Collins, and P.D. Jablonski, J. Power Sources, $\underline{168}$, 351 (2007).

17. D.E. Alman, and P.D. Jablonski, Inter. J. Hydrogen Energy, 32, 3743 (2007).

19. Z.G. Yang, G.G. Xia, P. Singh, and J.W. Stevenson, Solid State Ionics, 176, 1495 (2005). 


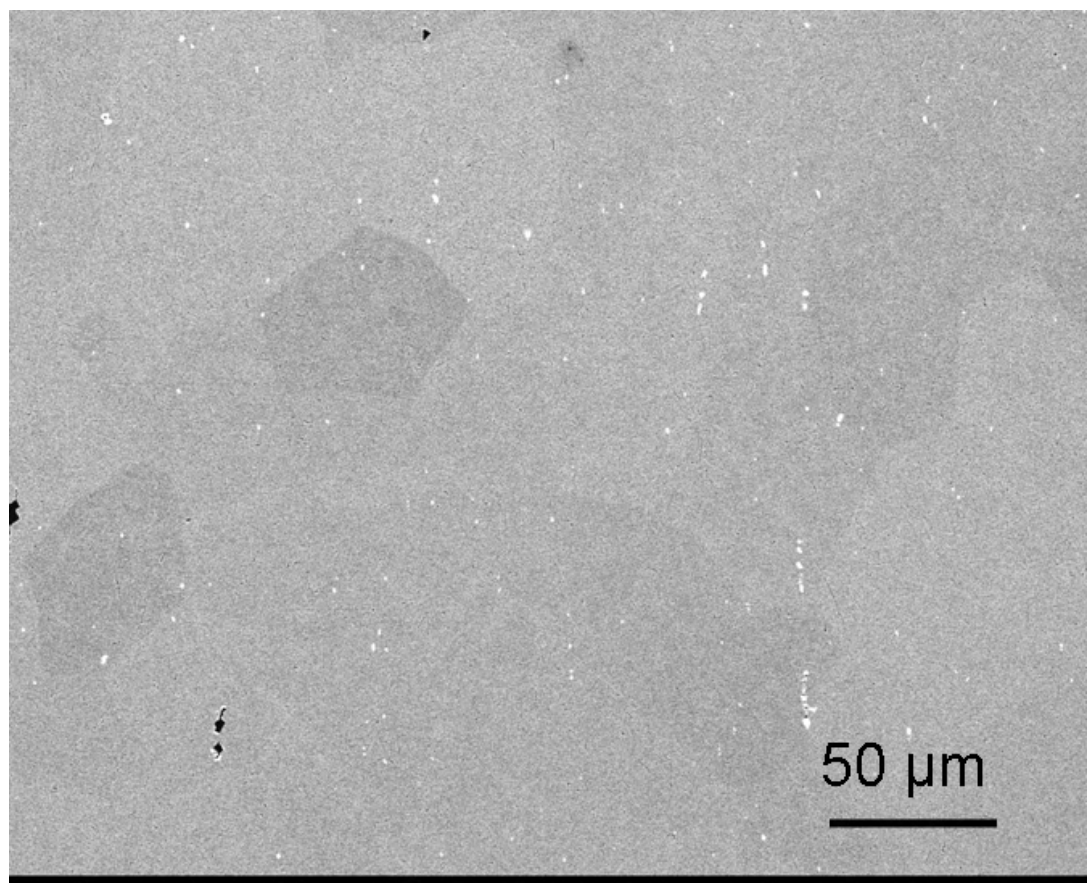

Figure 1. SEM image of polished 441 (as-received).

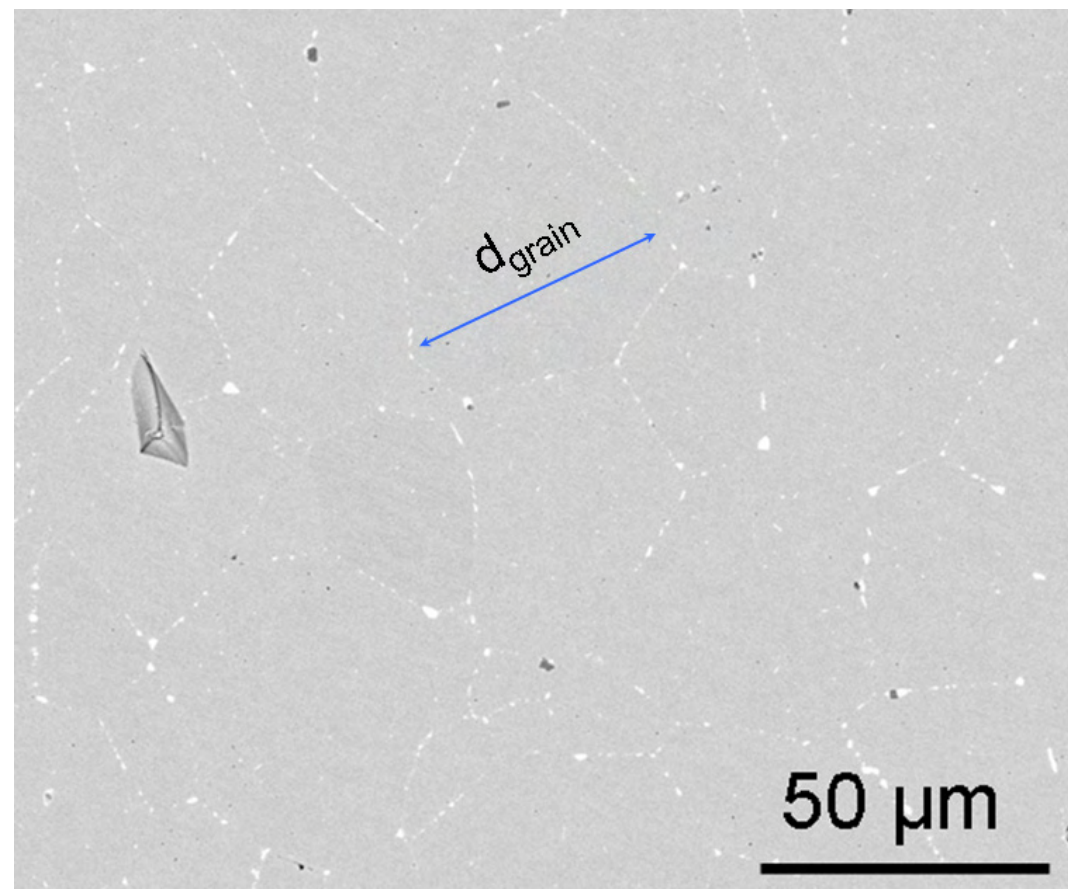

Figure 2. SEM image of polished 441 after oxidation in air for 300 hours at $800^{\circ} \mathrm{C}$. 
PNNL- 17568

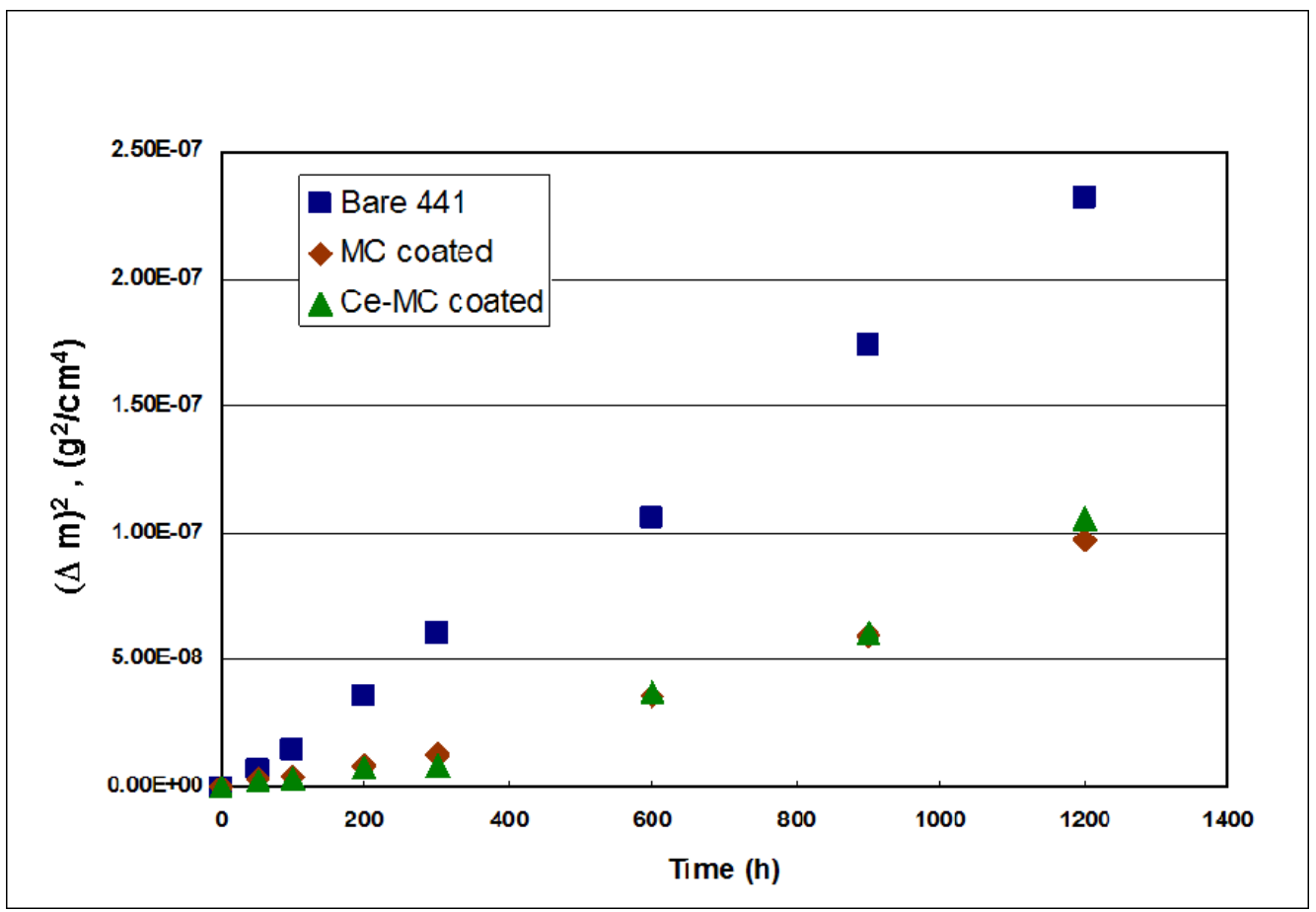

Figure 3. Weight gain, expressed as $(\Delta \mathrm{m})^{2}$, of bare 441 , MC spinel-coated 441 , and CeMC spinel-coated 441 as a function of time during oxidation in air at $800^{\circ} \mathrm{C}$.

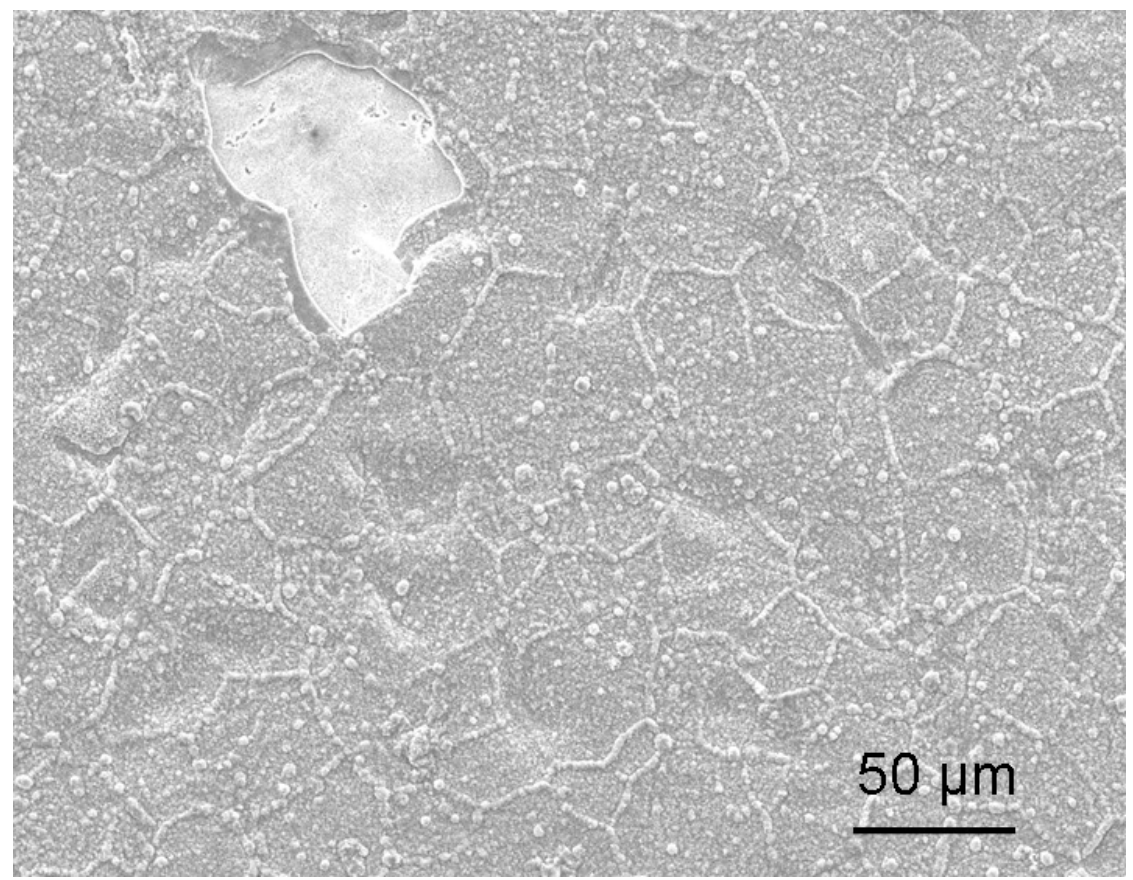

Figure 4. SEM surface image of 441 after oxidation at $800^{\circ} \mathrm{C}$ in air for 900 hours. Note surface oxide spallation. 
PNNL- 17568

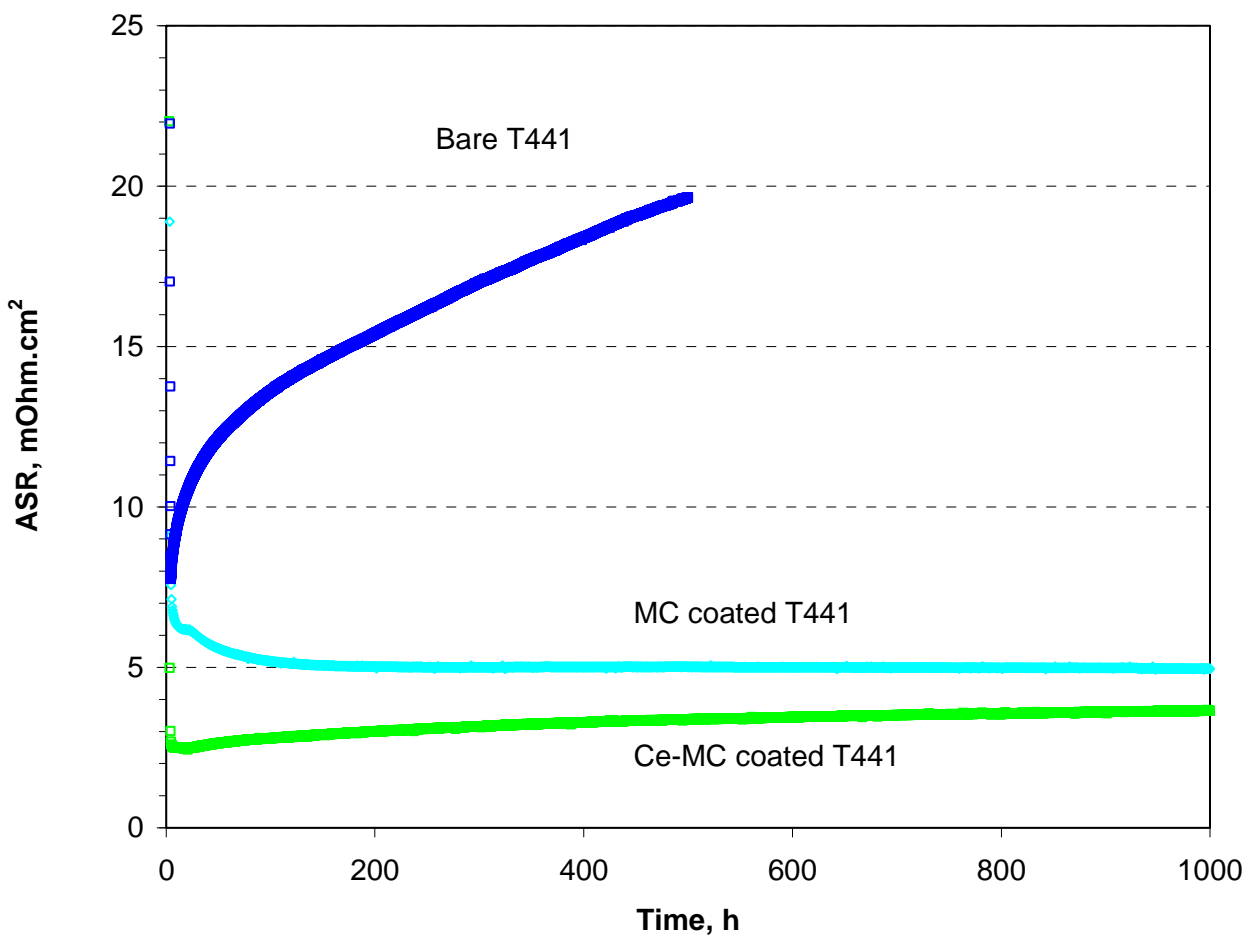

Figure 5. Area specific resistance (ASR) of bare 441, MC spinel-coated 441, and Ce-MC spinel-coated 441 as a function of time during oxidation in air at $800^{\circ} \mathrm{C}$. LSM was used as the contact paste.

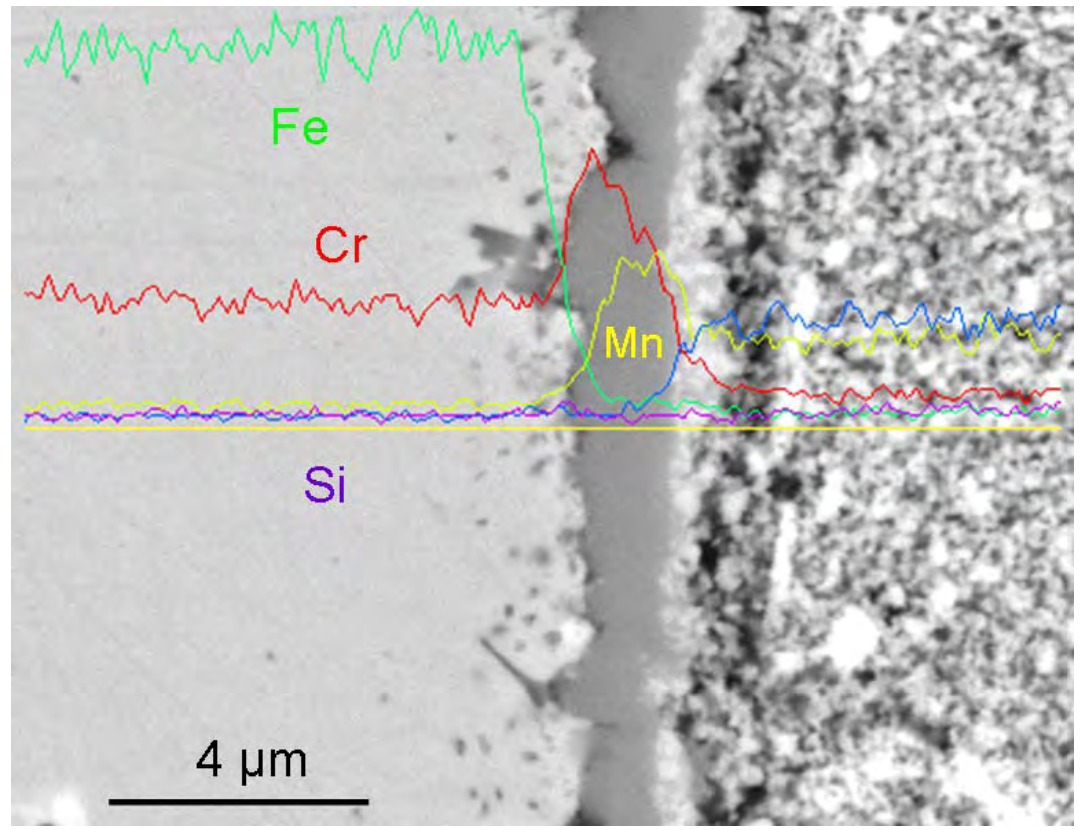

Figure 6. SEM cross-section image, with EDS line scan, of 441 after electrical evaluation at $800^{\circ} \mathrm{C}$ in air for 500 hours. Alloy is on left; LSM contact paste is on right. 


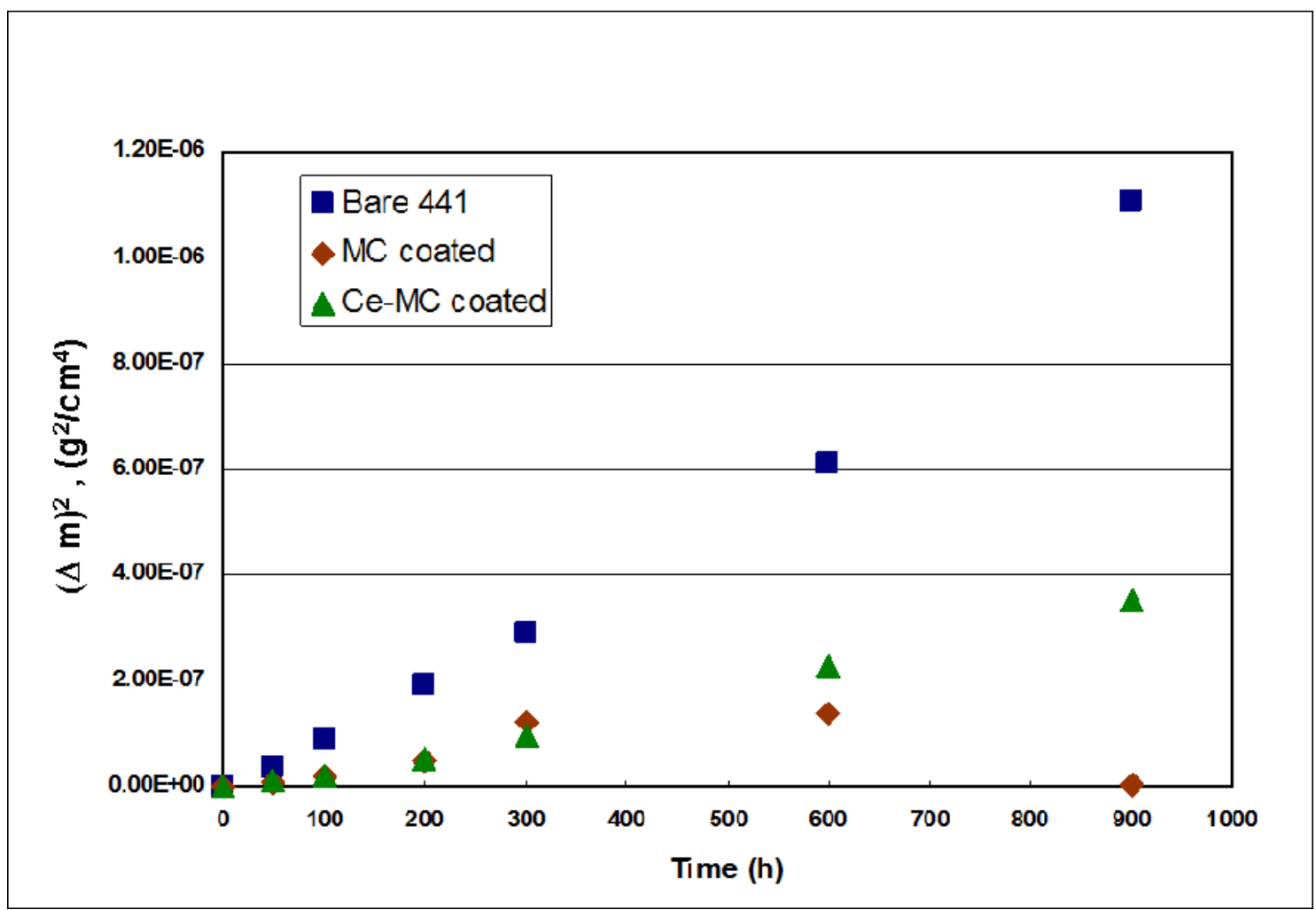

Figure 7. Weight gain, expressed as $(\Delta \mathrm{m})^{2}$, of bare 441, MC spinel-coated 441, and CeMC spinel-coated 441 as a function of time during oxidation in air at $850^{\circ} \mathrm{C}$. 


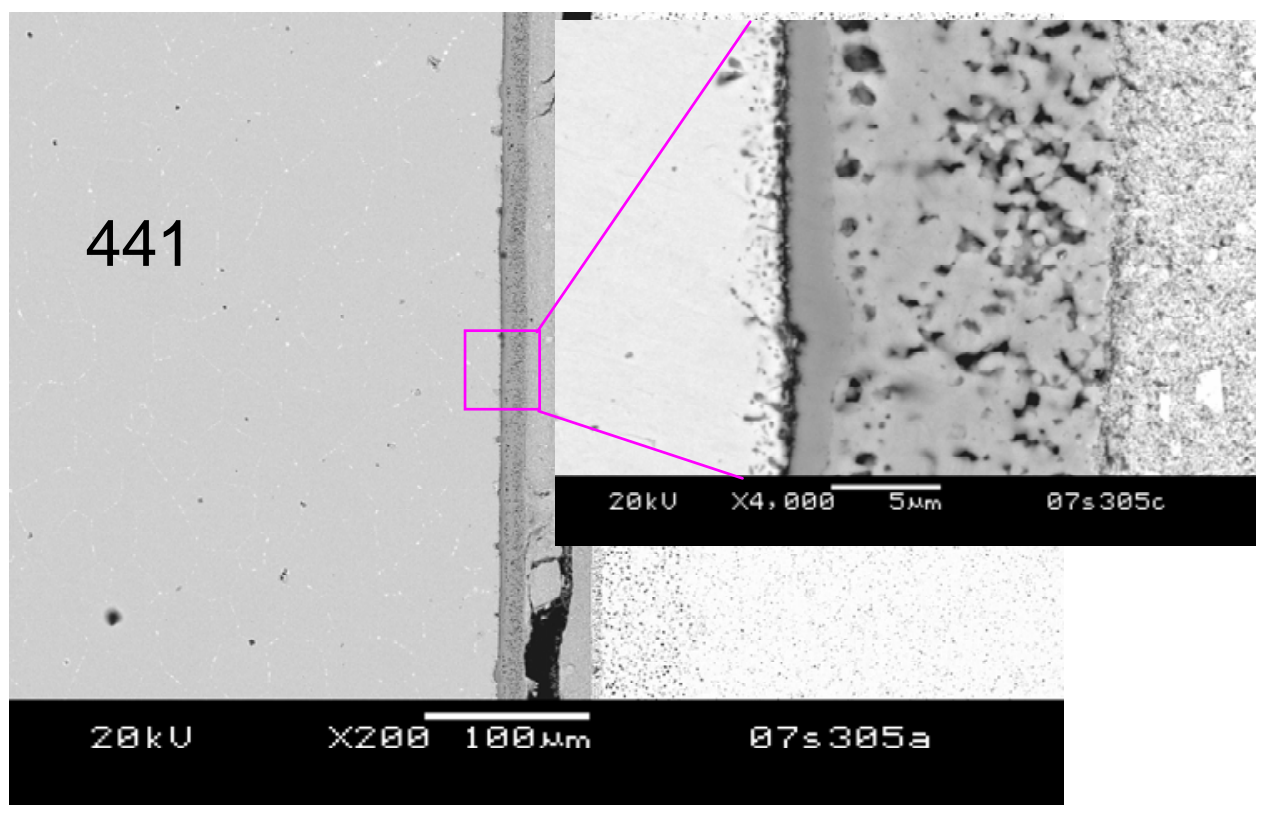

(a)

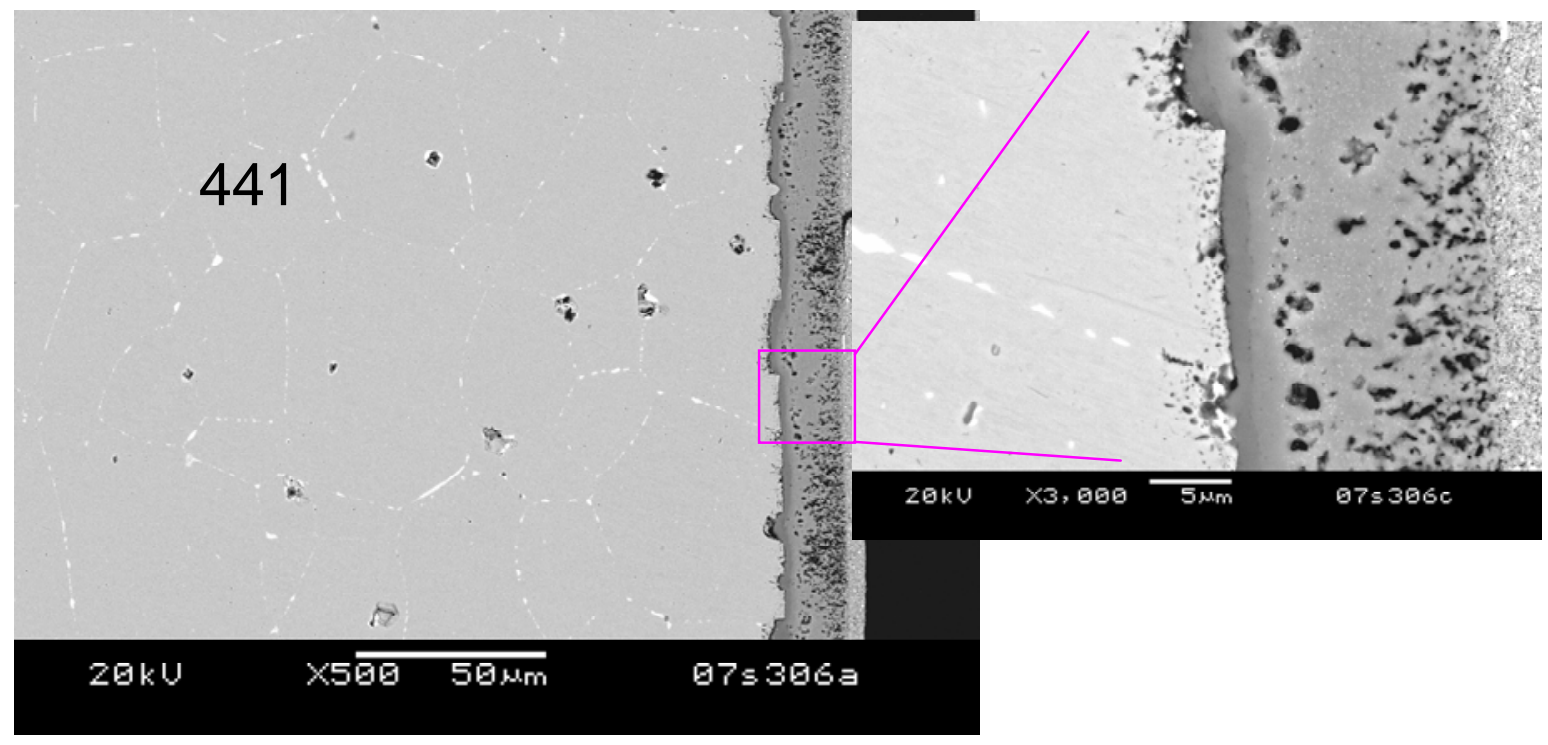

(b)

Figure 8. SEM cross-section images of (a) MC spinel-coated 441, and (b) Ce-MC spinelcoated 441 after 1,000 hours of electrical resistance testing in air at $800^{\circ} \mathrm{C}$. Alloy is on left; coating is in center; LSM contact paste is on right. 
PNNL- 17568



(a)

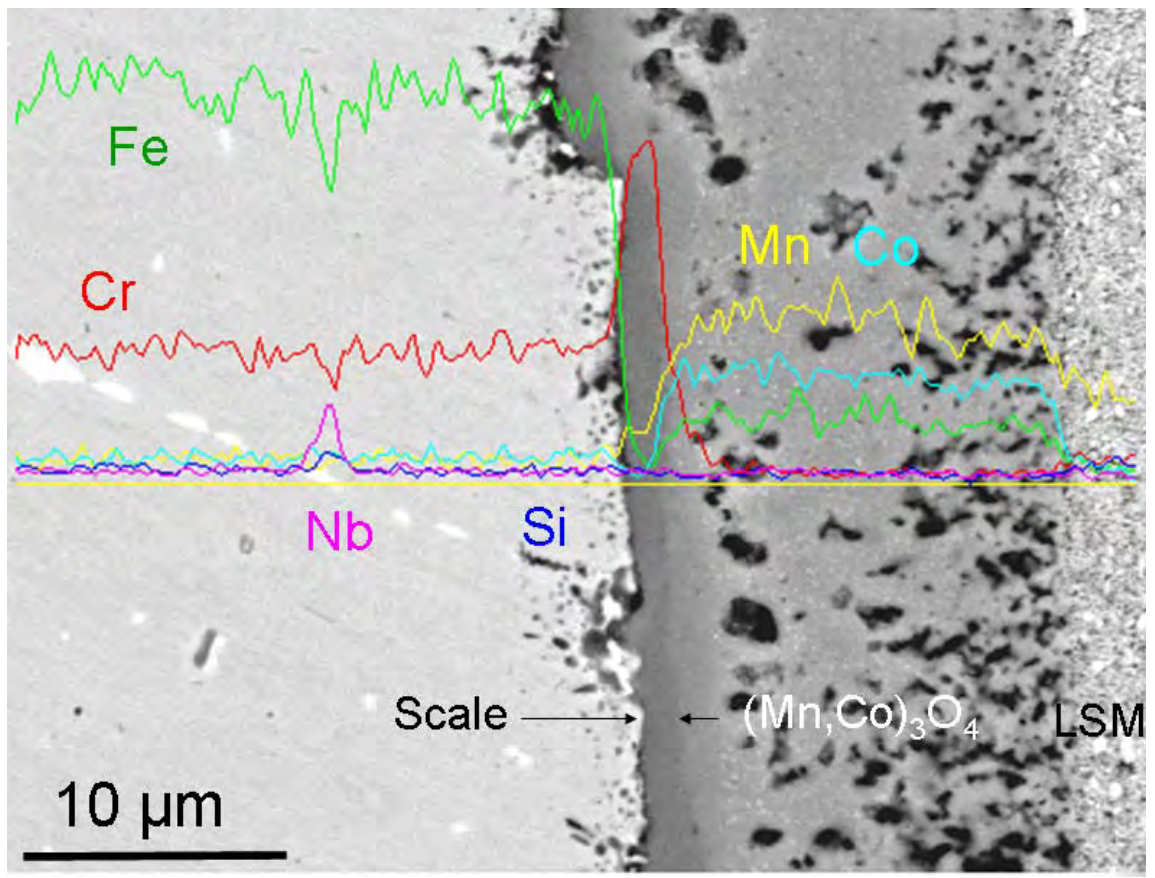

(b)

Figure 9. SEM/EDS cross-section images of (a) MC spinel-coated 441, and (b) Ce-MC spinel-coated 441 after 1,000 hours of electrical resistance testing in air at $800^{\circ} \mathrm{C}$. Alloy is on left; coating is in center; LSM contact paste is on right. 
PNNL- 17568

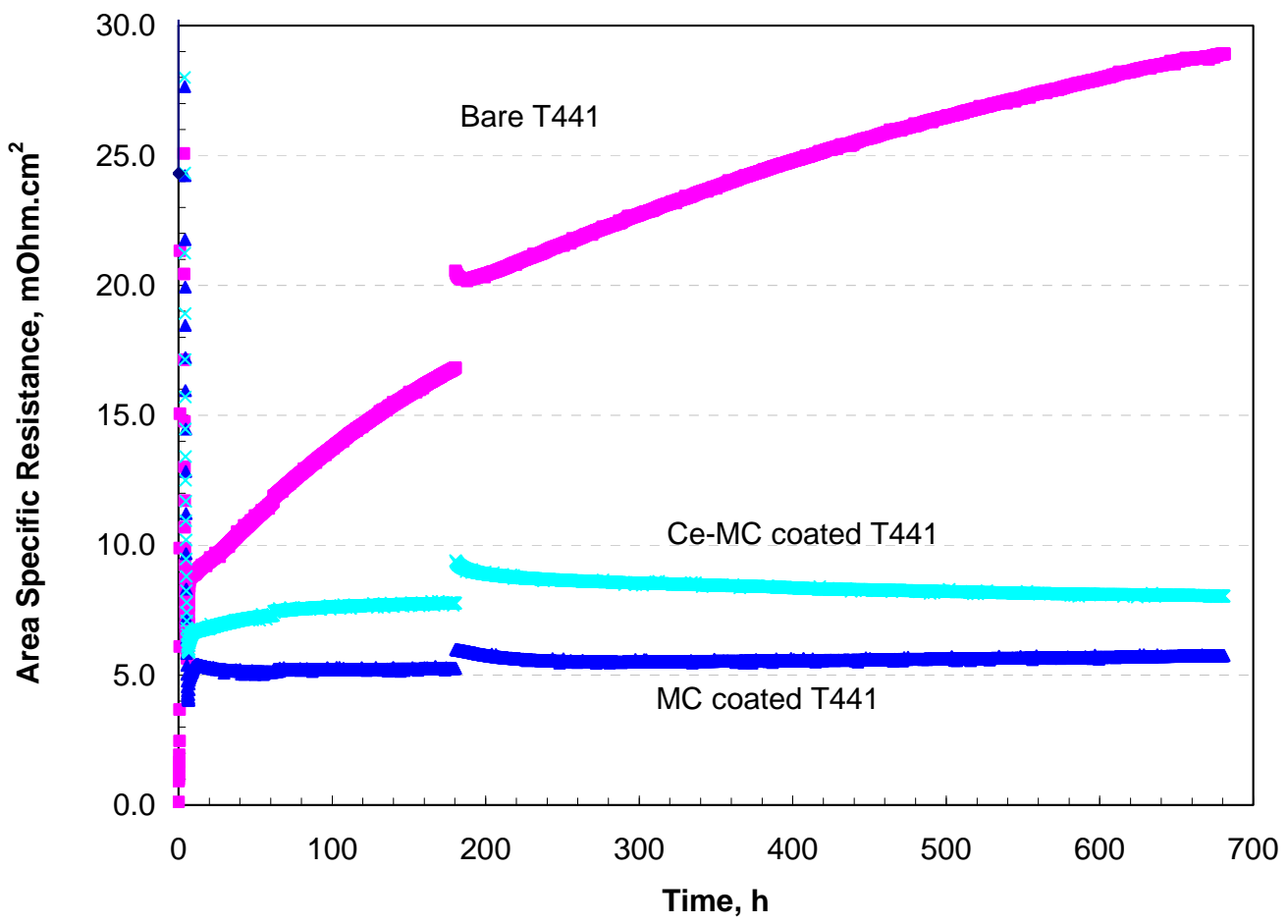

Figure 10. Area specific resistance (ASR) of bare 441, MC spinel-coated 441, and CeMC spinel-coated 441 as a function of time during oxidation in air at $850^{\circ} \mathrm{C}$. LSM was used as the contact paste. Tests were interrupted by an unscheduled power outage at 180 hours. 


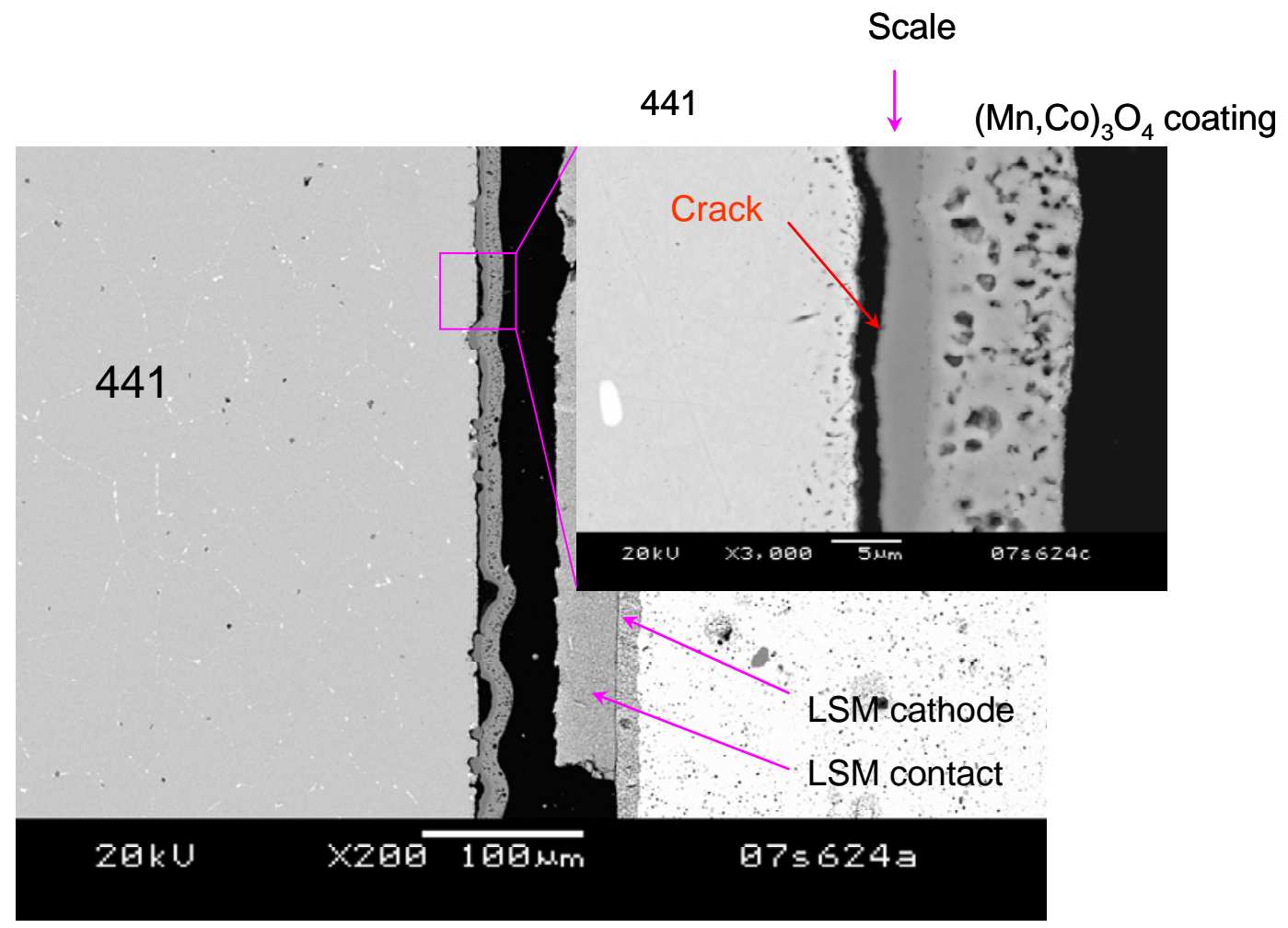

(a)

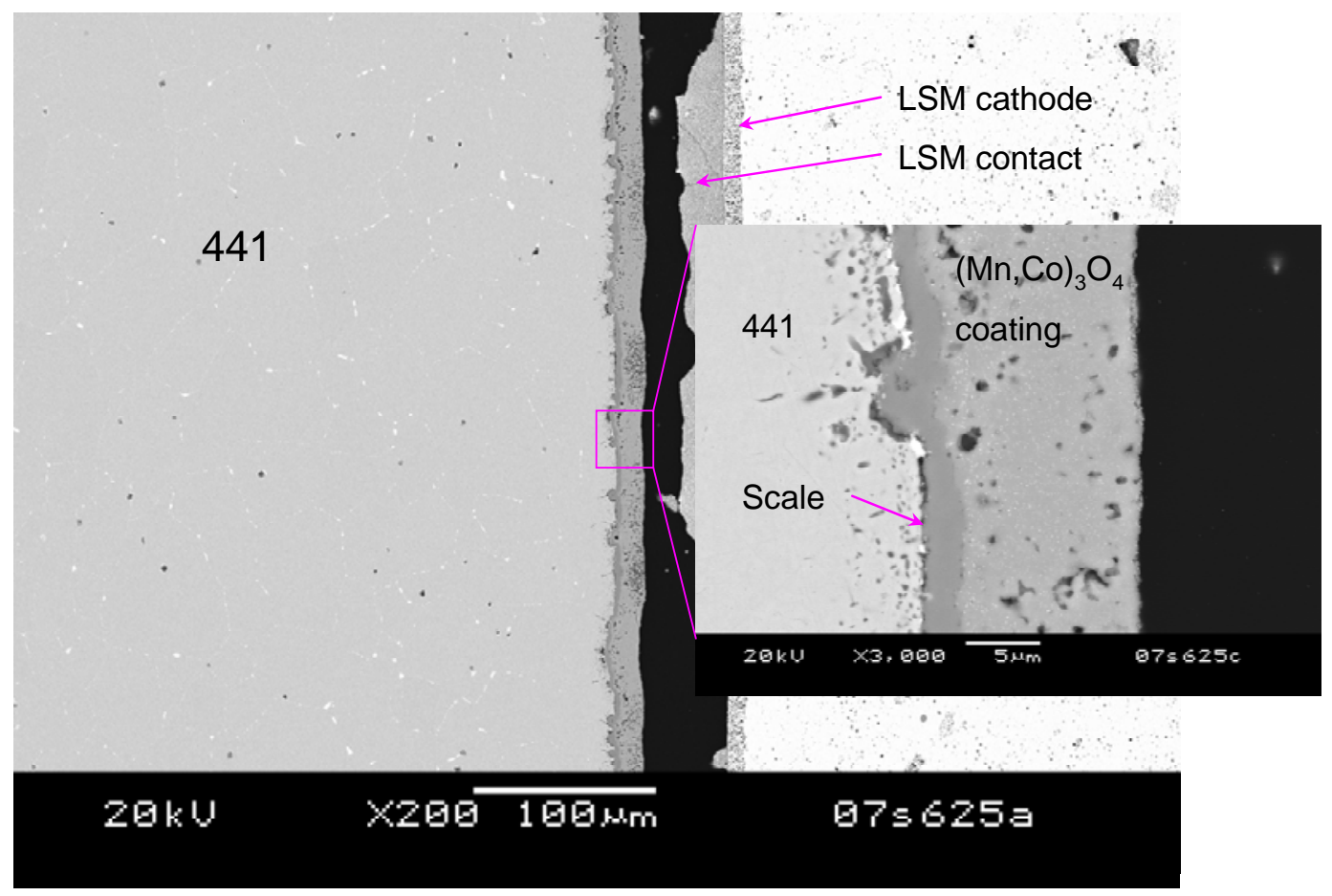

(b)

Figure 11. SEM cross-section images of (a) MC spinel-coated 441, and (b) Ce-MC spinel-coated 441 after 700 hours of electrical resistance testing in air at $850^{\circ} \mathrm{C}$. 
PNNL- 17568

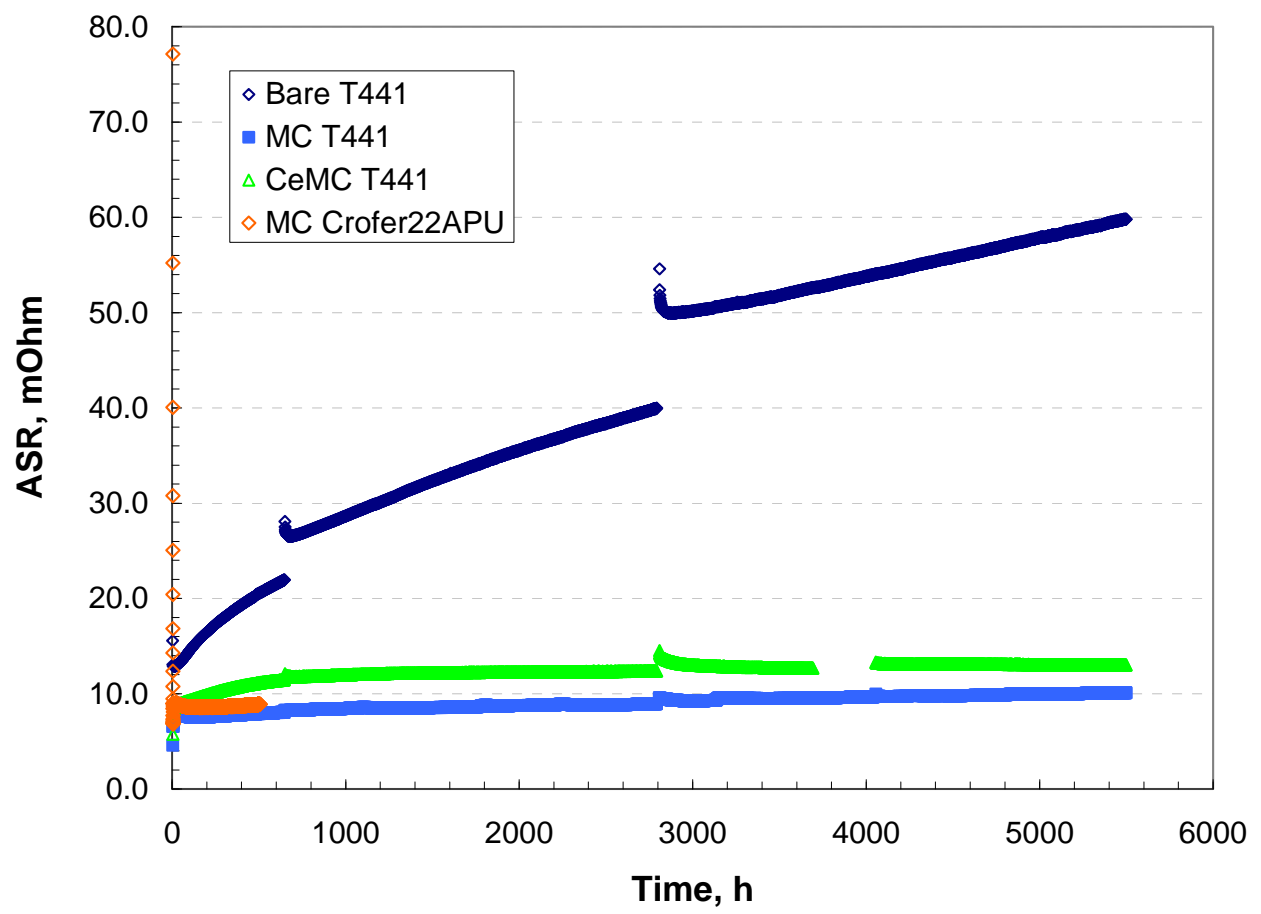

Figure 12. Area specific resistance (ASR) of bare 441, MC spinel-coated 441, and CeMC spinel-coated 441 as a function of time during oxidation in air at $800^{\circ} \mathrm{C}$. LSM was used as the contact paste. Tests were interrupted by unscheduled power outages at $\sim 650$ and 2800 hours. Previous ASR results for MC spinel-coated Crofer22APU are also shown for purposes of comparison. 
PNNL- 17568

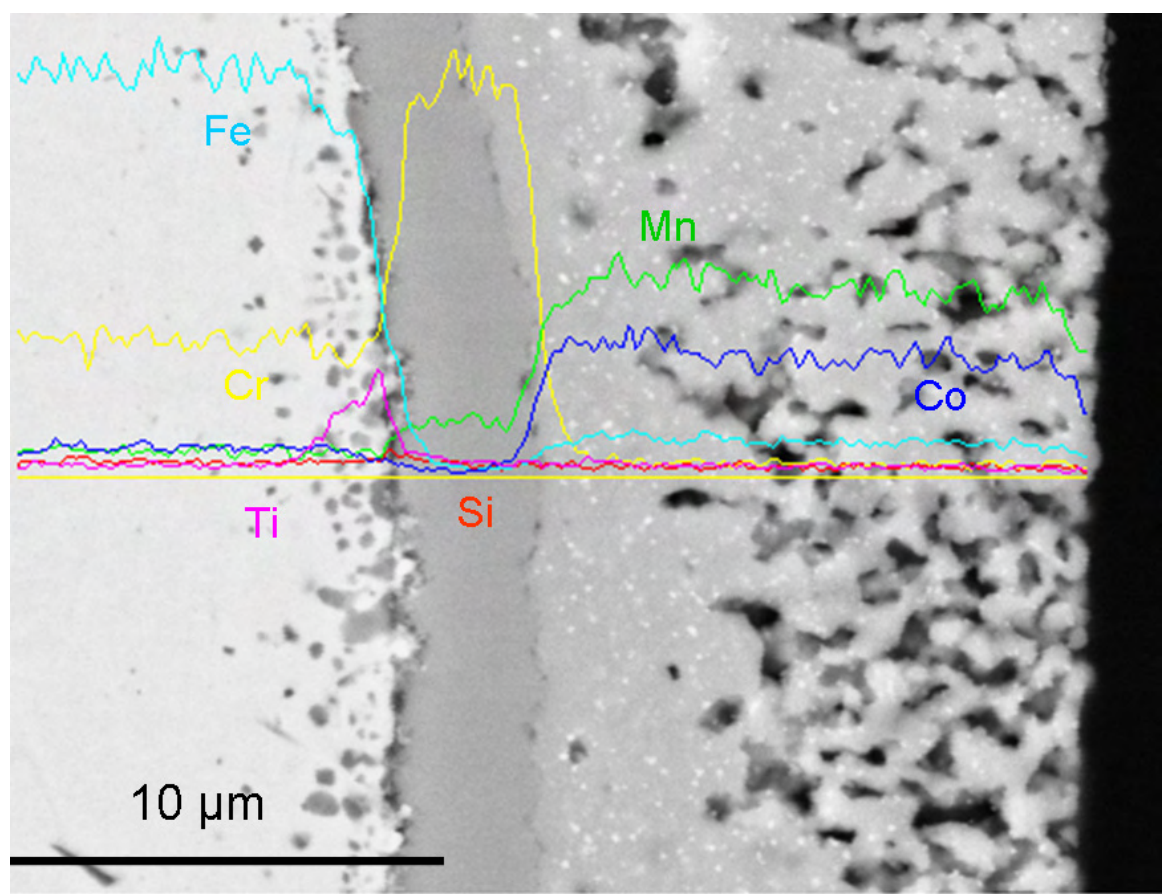

(a)

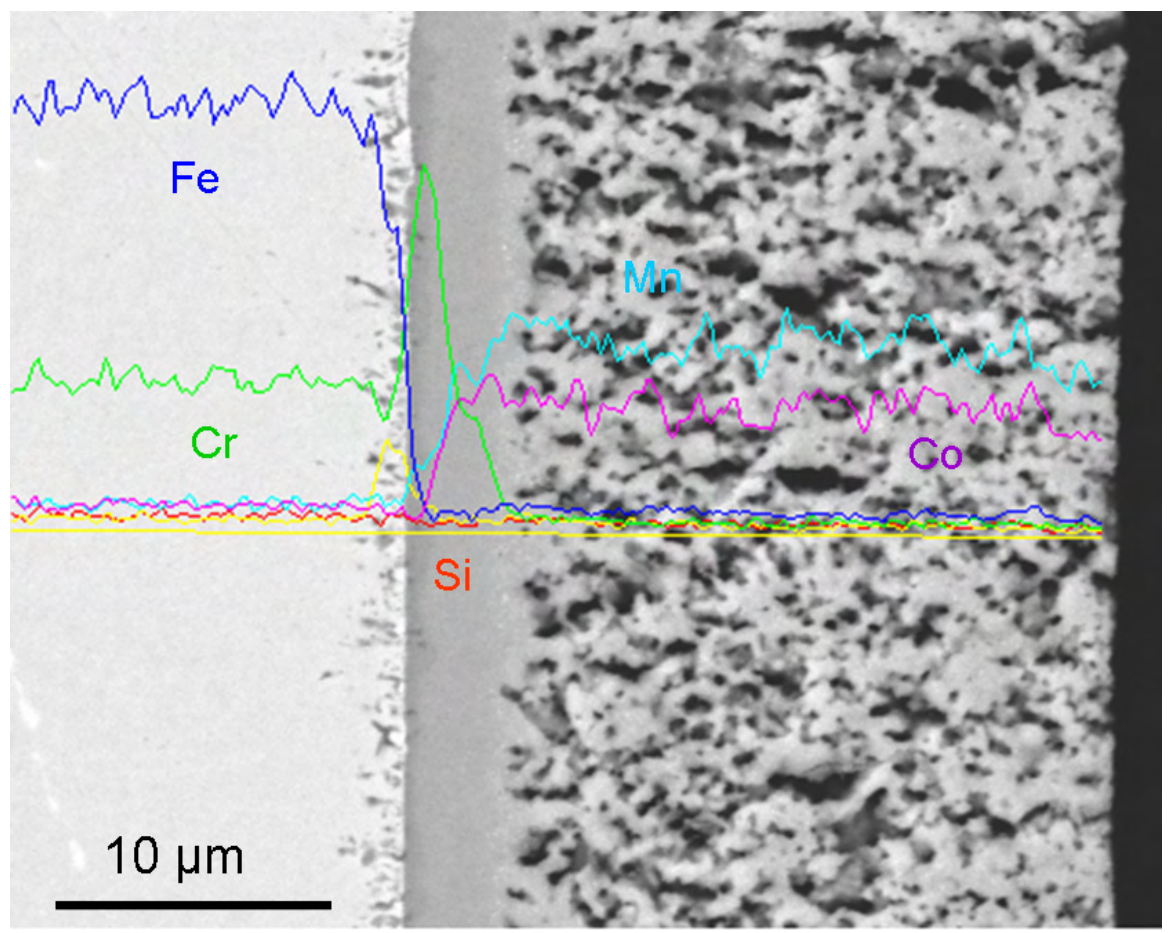

(b)

Figure 13. SEM/EDS of 441 coated with Ce-MC protection layers, after 1,000 hours of dual atmosphere exposure at $850^{\circ} \mathrm{C}$ : (a) one side of the sample that was exposed to air on both sides; (b) the air side of the sample that was simultaneously exposed to $97 \% \mathrm{H}_{2} / 3 \%$ $\mathrm{H}_{2} \mathrm{O}$ on the other side. 